\title{
Algorithm and methodology of diagnostics of communication system of the enterprise
}

\author{
Maxim Kravets ${ }^{1, *}$ \\ ${ }^{1}$ Voronezh state university, Universitetskaya Sq., 1, Voronezh, 394006, Russia
}

\begin{abstract}
On the basis of comparative analysis of approaches to the study of organizational communications developed a method of their diagnosis, consisting in determining the composition of the characteristics of the communication system of the enterprise, specialized methods for measuring and assessing the magnitude of critical deviations, and the research algorithm. Specifics of the considered strategic diagnostics consist in the accounting of resources and abilities of the organizational communications considered as complete set of external and internal communications. The resulting tools are used in decision-making procedures on the directions of development of the communication component of the strategic potential of the production enterprise. The tendency of alignment of the importance of communications supporting organizational changes with resource-providing communications with the increasing turbulence of the external environment is established, which increases the importance of internal communications for modern enterprises, including the distribution of budgets for the development of communications.
\end{abstract}

\section{Introduction}

Organizational communications play more and more significant role in strategic development of the enterprises, promoting improvement of the adaptable mechanism, creation of the innovative environment, the solution of a number of the most urgent problems of resource providing. For the Russian enterprises it is possible to note characteristic problems which elimination can be based on strategic approach to organizational communications: low innovative activity, low profitability, the shortage of long money for development of technological base, difficulties with involvement of qualified specialists and workers.

In genesis of the organizational communications can be allocated three key stages: 1) process, 2) network, 3) communication system of the enterprise. The presented chronology displays research preferences which evolve taking into account development of the theory of management and improvement of research tools. We are based on representation of communications as systems in scales of all organization. This approach allows the researcher to: 1) focus on the holistic characteristics of the object of study, which has a structural and environmental dimension, 2) reach the level of solving integration problems

*Corresponding author: share_kra@mail.ru 
of external and internal communications, 3) focus on key areas of improvement of the communication system of the enterprise, 4) explore the content of the communication capabilities of the enterprise.

A key tool for the development of the communication system of the enterprise is an adequate diagnostic methodology. Diagnosis differs from a simple assessment, because it involves the diagnosis, which not only determines the strategic problems of organizational communication, but also identifies the main causes and directions of their improvement. This approach corresponds to the generally accepted, but there are works that expand the understanding of diagnostics to the detailed planning and control of the implementation of strategic plans [30]. We consider the latter to be unproductive, since planning and control have their own developed methodology and are independent stages of strategic management.

\section{Methods}

Within the framework of diagnostics, we will consider the algorithm and methodology for the study of resources and capabilities of the communication system of the enterprise.

The specificity of our diagnostics of organizational communications is within the framework of the modern resource concept of strategic management, which along with traditional resources explores the communication abilities of the enterprise. The company's capabilities usually are measured by the experts on the point assessment of the resource pool and hierarchically nested capabilities. However, in the case of assessing the communication capability that supports organizational changes, we were able to form a more complex construct, in which points are set on the basis of a detailed description of the structural characteristics of the communication network obtained by us in the course of the study of communication interaction of Russian enterprises.

Analysis of the methodology of the study of organizational communications, in which we have identified common and specific methods, allowed us to specify the formed strategic scheme of evaluation of organizational communications: key communication resources $\rightarrow$ communication capabilities of the enterprise $\rightarrow$ the level of development of the communication system.

As a tool for assessing the communication climate, we prefer the methodology for assessing the internal climate of Costigan J.L., Schmeidler M.A. [1]. Communicative behavior produced by the company's management and projected on the rest of the communication. This approach has become quite common in the study of innovative work behavior.

As a basis for assessing the image of the manufacturing enterprise, we prefer the methodology Shkardun V.D., Akhtyamov T.M.[2], which has elements of image assessment for key target audiences (customers, partners, employees, government agencies, the public), which is best combined with the Russian communication practice of identifying key generalized stakeholders. This approach is widely used and numerous industry modifications. The assessment tools subjected to our audit from the point of view of important gauges in the emerging theory of informational transparency, crowdsourcing as an integral attribute of activity of the modern enterprise, as well as from the point of view of reduction of individual indicators that can be generalized or be found to be insignificant for certain categories of enterprise image [3]. A fundamentally different approach, consisting in the financial assessment of the company's image (Interbrand, EquiTrend, Young\&Rubicam, etc.), is not suitable for us in terms of diagnostic purposes, where the result should be a score, differentiated by the target audience [4].

Figure 1 presents a diagnostic algorithm that describes the procedure of the researcher to achieve the result of the problem, i.e. diagnosis, which identifies the problem and a 
possible solution.

Basic elements of diagnostics are communication capabilities of the enterprise which are derivatives of a complex of communication resources [5]. The resource-providing capability is calculated by groups of key stakeholders of different importance for the enterprise (which was confirmed by our study, including some groups considered by the management of organizations as insignificant), and the communication capability that supports organizational changes is calculated by two components: 1) the capability to receive information from the external environment (external ties of the core and periphery of communication network); 2) capability to discuss changes (internal communication network structure and communication climate).

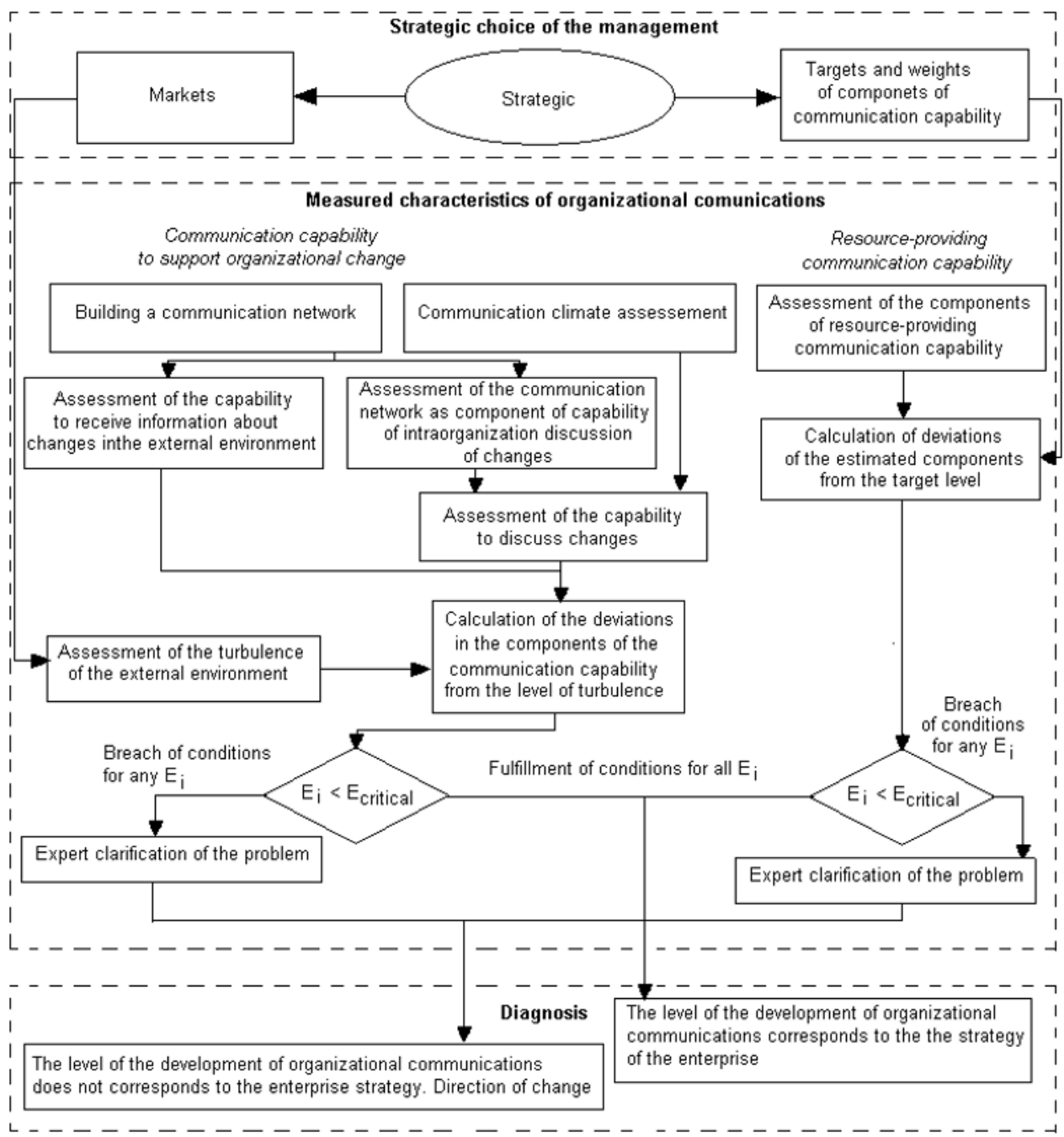

Fig. 1. Algorithm for diagnosing organizational communications.

The diagnosis is based on the idea of the strategic gap described by Ansoff I. and then received numerous confirmations. Criteria it is set at the level of divergence of 0.5 points (from the five-point scale) characteristics of the environment and targets set by the management with the calculated communication characteristics. This value is empirically justified by Ansoff I. and then confirmed by a number of domestic works to assess the 
potential of the enterprise.

The strategic gap in the communication capability supporting organizational changes is revealed in comparison with the level of turbulence of the external environment. The gap in the value of the resource-providing communication capability is revealed in discrepancy with the targets set by the chief executive officer together with the vice president of marketing [6, 7].

Even if the gaps are not identified, the level of communication system of the production enterprise is measured, which can be considered by management in order to improve it taking into account the current situation, forecasts, including possible scenarios of significant changes in the environment, and the strategic objectives of the enterprise.

\section{Results}

Calculation of the level of development of organizational communications and prioritization of investments of funds necessitate the determination of the importance (weight) of organizational communications. Weights are set by the management of the enterprise. In the face-to-face examination, the group makes an agreed decision.

Twelve enterprises of the Voronezh region were investigated, five of which were in the zone of high turbulence, seven in the low. The management of five enterprises has chosen a strategy of differentiation, seven adhere to the strategy of low costs.

For figure 2 the weights of the components of the basic division of enterprise communications are presented. As turbulence increases, the importance of communications as a component of the strategic potential that ensures the adaptability of the enterprise increases. In a stable environment, the management of companies prefers the communication resource-providing capability of the enterprise. It determines the long-term flow of resources. Russian consulting practice is focused today on the proposal to improve communications within the commercial function of the enterprise, however, as the survey of enterprise managers showed, when the turbulence of the external environment increases the importance of organizational communications as a component of the strategic potential that ensures the adaptability of the organization [8].

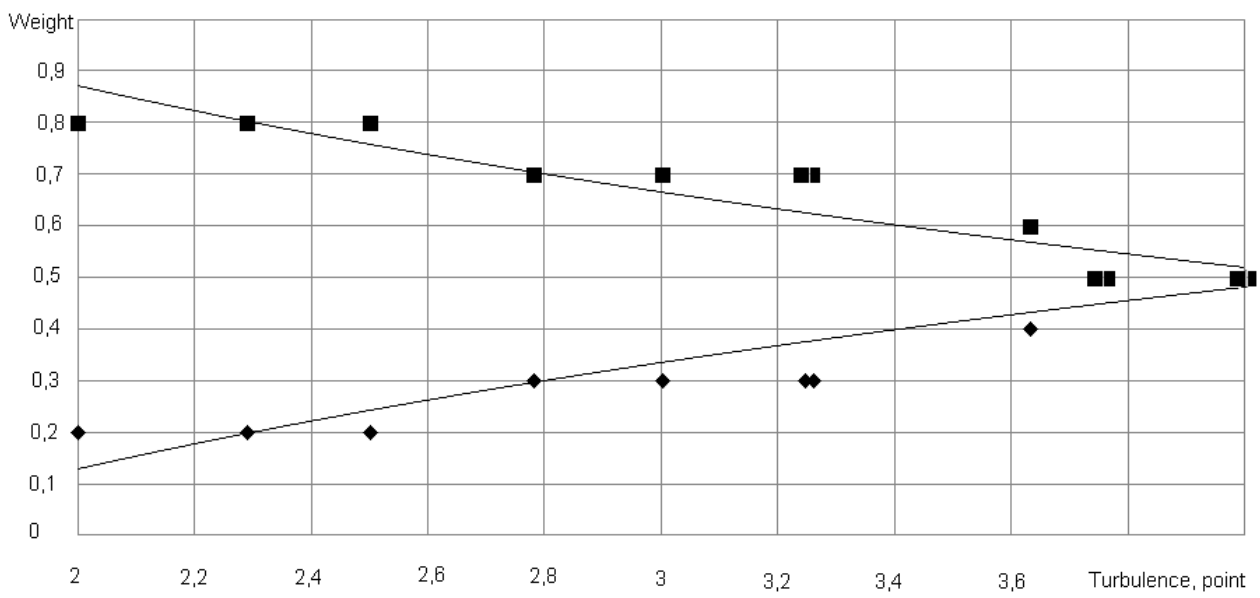

Fig. 2. Weight of enterprise communications: Square label: recourse-providing communication; Rhombus label: support organizational change communication

Distribution of the importance between obtaining information and its discussion concerning organizational changes of an essential difference hasn't shown. In only two 
cases the management of the enterprise has defined the big importance of ability of obtaining information from the external environment. Therefore assessment of weight of these abilities can be not carried out further.

Assessment of the importance of communications with various groups of stakeholders (customers, employees, partners, governance agencies, the public) has shown that they are very not equivalent that in general is coordinated with the research conducted by Chernov D.V. [9].

A number of the studied enterprises are focused in their communications mainly on customers and to a small extent on employees. The importance of forming a positive image of the company in government agencies and the public recognized as significant in only two cases out of twelve. At the same time, as a positive point, it should be noted that to some extent all enterprises recognize the need to form a positive image of the employer, which is today one of the conditions for attracting employees of the necessary qualifications on a long-term basis. The importance of long-term communications aimed at creating a positive business image and being a distinctive feature of a foreign enterprise is not recognized by all Russian enterprises. The importance of these communications is recognized in $67 \%$, and the weight of this category does not exceed 0.2 , which is significantly lower than not only the client's stakeholder, but also the employee's stakeholder.

The level of development (LD) of the communication system of the production enterprise in our case is calculated by summing all the communication abilities of the enterprise, taking into account their importance:

$$
L D=W_{C H} \times \frac{C_{C H . E x t e r n a l}+C_{C H . I n t e r n a l}}{2}+W_{R} \times \sum \omega_{i} \cdot C_{R i}
$$

Where: $W_{C H}, W_{R}$ - weights that determine the value of communication capabilities (supporting organizational changes, providing resources); $\omega_{i}$ significance of $i$-th component of resource-providing capability.

Formulas 2, 3 represent the calculation capability to obtain information from the external environment and its discussion within the organization, obtained by summing the estimates of the developed assessment tools.

$$
\begin{gathered}
C_{C H . \text { External }}=\frac{1}{2 \times n} \sum_{i}\left(R_{\text {network.core.external.i }}+R_{\text {network..periphery.external. } i}\right) \\
C_{C H . \text { Internal }}=\frac{1}{2}\left(\sum_{i} \frac{\left(R_{\text {network.core.internal.i }}+R_{\text {network.periphery.internal. } i}\right)}{2 \times n}+\sum_{j} \frac{R_{\text {climate.j }}}{m}\right)
\end{gathered}
$$

In formulas 2 and $3 n$ - number of experts, $m$ - number of employees interviewed.

Formulas 4-9 represent the calculation components of the resource-providing capability as a combination of key resources: communication skills of sales and service employees, feedback from consumers, corporate image.

$$
\begin{gathered}
C_{R . \text { sale }}=\frac{1}{2 \times n}\left(\sum_{i} R_{\text {communication.skill. } i}+\sum_{i} \sum_{j} \frac{R_{\text {image.customer. } . . j}}{m}\right) \\
C_{R . \text { feedback }}=\frac{1}{n \times m} \sum_{i} \sum_{j} R_{\text {feedback. } . . j}
\end{gathered}
$$




$$
\begin{aligned}
& C_{\text {R.image.bisness }}=\frac{1}{n \times m} \sum_{i} \sum_{j} R_{\text {image.bisness.i.j }} \\
& C_{\text {R.image.employee }}=\frac{1}{n \times m} \sum_{i} \sum_{j} R_{\text {image.employee.i.j }} \\
& C_{\text {R.image.state }}=\frac{1}{n \times m} \sum_{i} \sum_{j} R_{\text {image.state.i.j }} \\
& C_{\text {R.image.public }}=\frac{1}{n \times m} \sum_{i} \sum_{j} R_{\text {image.public.i.j }}
\end{aligned}
$$

In formulas 4-9 $j$ is the component of the estimate ( $m$ - number of components); $i$ evaluation of the representative of the target group ( $n$ - number of respondents).

To clarify the problem, you may need additional information about the elements of the internal environment of the enterprise and the study of individual elements of organizational communications.

With regard to the communication capability supporting organizational change, information is needed on the organizational structure and forms of communication activity associated with organizational changes that may occur both on a regular basis (meetings, working groups, development board) and on a non-permanent basis (meetings to address specific problems collected at the level of management of the company).

With regard to the resource-providing communication capability, it is necessary to conduct a thorough audit of the company's policies, since communications in relation to them significantly determine both the level of information openness and the perception of the organization by stakeholders [9].

Information openness of the company can play it only positive, but also a negative role in the formation of stable relationships with stakeholders. Any of the proclaimed principles can lead to both a negative public discussion and the deterioration of the company's reputation. Therefore, it is necessary to discuss such principles for a sufficient period of time (at least one month), both in the group engaged in the formation of communicative goals, and, if necessary, in the organization as a whole.

The process of forming the organization's strategic communication goals, based solely on information about the mission, vision and strategic goals, is unreasonably risky, due to ignoring the negative impact of the most important factors of the external and internal environment on the company's activities.

The initial stage of the algorithm for the formation of strategic communication goals is the mission and vision of the enterprise. If the objectives of the activity are not reflected in detail in the relevant documentation, the task of the communicative strategy developers is to survey the management for their vision of promising areas of activity, the mission of the enterprise.

The next stage involves the development of common goals of the organization: increasing market share, improving the quality of products and services, diversification of products and services, reducing production costs in comparison with the main competitors, etc. If these goals are not documented, then the developers of communication goals interview the management or invite him to a meeting of the group to clarify the goals. In the case where the user experiences difficulties with the quantitative formulation of strategic objectives it is doing so efficiently. Then there are grounds for the third stage of the algorithm of formation of communicative purposes.

Implementation of the enterprise strategy is carried out through the application of implementation policies, i.e. the fundamental rules of strategic decision-making, which are 
mainly functional specifics. Policies can be thoroughly refined in the sectoral context.

Vihanskij O.S., Naumov A.I. note the importance of defining the organization's policies: "along with the strategies in the strategic management of the organization, the rules play a big role, which, as well as the strategies, determine the functioning of the organization, but unlike the strategies in an explicit form, do not have a target beginning. They are mostly restrictive or prescriptive, creating an atmosphere in which activities are carried out" [10].

Any of the declared policies in the appropriate negative interpretation may entail a public response, resulting in a deterioration of the image of the enterprise. Conversely, some of the policies that seem questionable in the implementation of the strategy in practice prove their expediency and effectiveness.

For the convenience of the formulation of communicative purposes, a formal correlation of the company's policy with its strategic goals by means of letters or numbers is used. So, let's define the following strategic goal by letter $A$ : reduction of production costs in comparison with competitors. In the implementation policies, we denote by the letter $A$ the following policies: hiring specialists without experience, components from China, etc.

The established policies for the implementation of the strategy should be analyzed for, first, possible negative opinions, and, if necessary, actions, subjects of the external and internal environment, and secondly, positive feedback from subjects of the external and internal environment. The results of the analysis are recorded under the appropriate letter or number. In continuation of the example, we will indicate the following positive opinion $+A$ : shareholders and management of the company will positively perceive the reduction in the cost of production operations; and negative opinions $-A$ : consumers may be afraid of low-quality products [10].

The formulation of stakeholder views on the strategy implementation policies involves identifying specific stakeholders and assessing their impact on the organization's activities. Some of the stakeholders of the enterprise are quite obvious, but there are also those that require careful search and identification. The collection of information on them provides for the preliminary solution of the following questions. What is necessary to know about the interested persons? Where and how can I get the necessary information? Who will be responsible for the collection, analysis and interpretation of the data? How can information be protected from unauthorized or misuse?

The identified stakeholders can be ranked according to the degree of influence, which will make it possible to determine the communicative priorities and use the resources of the enterprise more effectively. The ranking of stakeholders should take into account the strength of the following factors: the availability of resources for counteraction, participation in political and trade unions, public support, dedication to confrontation.

\section{Discussion}

Only at this stage, and not immediately after setting the goals of the overall strategy, it is possible to formulate strategic communication goals. If possible, communication objectives should be quantified. In the case when the quantitative formulation of the communicative purpose is difficult, it is formulated qualitatively, indicating the direction of application of communicative efforts of employees of the enterprise. Many foreign companies formulate the majority of communicative goals qualitatively, which is due to a number of reasons: 1) the company often lacks real tools for measuring the achievement of communicative goals, 2) communicative goals are secondary for most functional managers of the enterprise, and 
the primary operational goals of the relevant department, 3) strategic communication goals are still detailed in lower-level plans, for example, promotion of a new product, opening a branch - all this requires precise formulation of communication goals, at least related to informing potential customers [11].

Area of concern resource-providing communications capability may become low communicative competence of employee's sales and customer service departments. The most obvious area of analysis is the assessment of knowledge and skills obtained by diplomas, which is a simple and fast method of evaluation. Nevertheless, more complex methods can be used to assess this group of competencies: $360^{\circ}$ assessment, business game, competency interviews. To improve the objectivity of the study of competencies and desirable mapping of communicative competencies for different groups of employees.

Additional research may be needed to assess the effectiveness of the use of communication tools, their compliance with the target audience, the study of the content of messages.

The calculation of the level of development of the communication system of the enterprise allows to determine the current state of organizational communications and to determine standard measures for their further development, if the management considers their development inappropriate to the current tasks or predicts the need to increase them due to future changes in the environment [12].

For the structure of communications, we have obtained a graphical model, justified the criteria of importance of individuals in the periphery of the communication network and received a normative description, which generally makes it possible to improve individual communications and communications of the entire enterprise. The sequence of improving the communication network of the production enterprise can be represented as follows.

1) The requirements to the core of the network are checked, i.e. centralization, density of interaction and presence of external relations of members of the strategic team are checked. Individual relationships can be established quickly (unless there are serious conflicts and motivational problems), but the fundamental difference with the norm, as a rule, requires the development of a program of changes, a significant change in the attitude to communication from the management.

2) Peripheral requirements are checked. First, the number of isolationists that can exist only at low levels of turbulence (repetitive, expanding) is calculated. A common constraint for industrial enterprises, even with a stable environment and a simple technological base, is a level of $7 \%$, the excess of which can create problems for planned changes associated with both lack of employee involvement and possible staff turnover. With high turbulence, the presence of isolationists is unacceptable. Secondly, the total density of interaction is checked, group and intergroup interaction is visually analyzed. The correction of individual links is carried out, in case of significant deviations, a program for the development of the communication network is developed. Third, the presence of external relations and their diversity are analyzed. Fourth, identified critical in terms of decisions made in the core of the periphery of the staff (employees with external relations and a significant indicator of knowledge). Based on the workload of the head of the enterprise (including taking into account its external communication activity), direct connections to the most important employees of the periphery are designed, the other significant employees should have direct connections with other members of the strategic core. As a result, there should be no significant employees located at a distance of more than two ties from the general manager.

\section{Conclusion}

Thus, based on a comparative analysis of approaches and tools for investigating external and internal communications of the enterprise, an algorithm was developed and a method 
for diagnosing organizational communications was developed, consisting in determining the composition of the characteristics of the communication system of a manufacturing enterprise, specialized methods for measuring them, and estimating the magnitude of critical deviations.

\section{References}

1. J. Costigan, M. Schmeidler, The 1984 handbook for group facilitators San Diego (1984)

2. C.J. Adcock, N. Meade, European Journal of Operational Research 259(2), 746-765 (2017)

3. C. Furlong, S. De Silva, K. Gan, L. Guthrie, R. Considine, Journal of Environmental Management 191, 83-95 (2017)

4. K. Usanova, A. Rechinsky, N. Vatin, Applied Mechanics and Materials, 635-637, 2090-2094 (2014)

5. V. Shkardun, T. Ahtyamov, Marketing v Rossii i za rubezhom 3 (2001)

6. I. Ansoff, Strategic Management (1979)

7. D. Chernov, Strategicheskie kommunikacii rossijskogo biznesa (2009)

8. O. Vihanskij, A. Naumov, Menedzhment (2014)

9. R. Brazauskas, J. Le-Rademacher, Computer Methods and Programs in Biomedicine 135, 199-207 (2016)

10. I. N. Priadko, V.P. Mushchanov, H. Bartolo, N. I. Vatin, I.N. Rudnieva, Magazine of Civil Engineering, 65 (5), 27-41 (2016) DOI: 10.5862/MCE.65.3

11. I. Kardes, A. Ozturk, S.T. Cavusgil, E. Cavusgil, International Business Review 22, 905-917 (2013)

12. E.K. Chirkunova, E.E. Kireeva, A.D. Kornilova, J.S. Pschenichnikova, Procedia Engineering 153, 112-117 (2016) 